\title{
Low-Frequency Vibration Sensor with a Sub-nm Sensitivity Using a Bidomain Lithium Niobate Crystal
}

\author{
Ilya V. Kubasov ${ }^{1, * D}$, Aleksandr M. Kislyuk ${ }^{1}$, Andrei V. Turutin ${ }^{1,2}{ }^{\mathbb{D}}$, Alexander S. Bykov ${ }^{1}$, \\ Dmitry A. Kiselev ${ }^{1}$, Aleksandr A. Temirov ${ }^{1}$, Roman N. Zhukov ${ }^{1}$, Nikolai A. Sobolev 1,2 ${ }^{\mathbb{D}}$, \\ Mikhail D. Malinkovich ${ }^{1}$ and Yuriy N. Parkhomenko ${ }^{1}$ \\ 1 Department of the Materials Science of Semiconductors and Dielectrics, National University of Science and \\ Technology MISiS, 119049 Moscow, Russia; akislyuk94@gmail.com (A.M.K.); aturutin92@gmail.com (A.V.T.); \\ xalexx1349@mail.ru (A.S.B.); dm.kiselev@gmail.com (D.A.K.); temirov.alex@yandex.ru (A.A.T.); \\ rom_zhuk@mail.ru (R.N.Z.); sobolev@ua.pt (N.A.S.); malinkovich@yandex.ru (M.D.M.); \\ parkh@rambler.ru (Y.N.P.) \\ 2 Department of Physics and I3N, University of Aveiro, 3810-193 Aveiro, Portugal \\ * Correspondence: kubasov.ilya@gmail.com
}

Received: 27 December 2018; Accepted: 30 January 2019; Published: 1 February 2019

\begin{abstract}
We present a low-frequency sensor for the detection of vibrations, with a sub-nm amplitude, based on a cantilever made of a single-crystalline lithium niobate $\left(\mathrm{LiNbO}_{3}\right)$ plate, with a bidomain ferroelectric structure. The sensitivity of the sensor-to-sinusoidal vibrational excitations was measured in terms of displacement as well as of acceleration amplitude. We show a linear behavior of the response, with the vibrational displacement amplitude in the entire studied frequency range up to $150 \mathrm{~Hz}$. The sensitivity of the developed sensor varies from minimum values of $20 \mu \mathrm{V} / \mathrm{nm}$ and $7 \mathrm{~V} / g$ (where $g=9.81 \mathrm{~m} / \mathrm{s}^{2}$ is the gravitational acceleration), at a frequency of $23 \mathrm{~Hz}$, to peak values of $92.5 \mathrm{mV} / \mathrm{nm}$ and $2443 \mathrm{~V} / \mathrm{g}$, at the mechanical resonance of the cantilever at $97.25 \mathrm{~Hz}$. The smallest detectable vibration depended on the excitation frequency and varied from $100 \mathrm{~nm}$, at $7 \mathrm{~Hz}$, to $0.1 \mathrm{~nm}$, at frequencies above $38 \mathrm{~Hz}$. Sensors using bidomain lithium niobate single crystals, as sensitive elements, are promising for the detection of ultra-weak low-frequency vibrations in a wide temperature range and in harsh environments.
\end{abstract}

Keywords: lithium niobate; bidomain crystal; vibration; sensor

\section{Introduction}

Precise measurements of weak vibrations are of interest for structural health monitoring [1-3], security [4], and active vibration damping [5-7]. In order to detect a vibration, it is necessary to convert the energy of an oscillatory movement to an electrical signal. Optical and piezoelectric sensors are the most frequently used devices for this purpose [8]. The optical vibration sensors are usually more precise and sensitive but have large sizes and a high power consumption; hence they are expensive and inconvenient to be used as parts of, for example, a distributed network in complex constructions. On the contrary, devices that use the piezoelectric effect to detect vibrations are simple, small, and able to operate both in active (as surface acoustic wave structures [9]) and passive (bending, shear, or torsion mechano-electric converters [10-12]) regimes. Moreover, a complex vibrational sensing network can be initialized from a standby mode by a single passive piezoelectric detector [13]. It is also an advantage that the piezoelectric sensors can be designed so as to harvest mechanical energy of vibrations and transform it to electricity, thus enabling the creation of self-powered devices [14]. 
In spite of the fact that a large number of different shapes and designs of the piezoelectric sensitive elements were offered, only a few materials were tested. Commonly, the sensors contain lead zirconate titanate (PZT) ceramics, having different compositions and states (e.g., films [11,12,15], bulk ceramics [13,16-20], or fiber composites [21]), although for high-temperature applications single crystals of quartz [22], langasite [23], lithium niobate (LN) [24], yttrium oxyborate [25], and aluminum nitride films [10] were also suggested. Good reviews on this topic can be found in $[8,24,26]$. Despite the fact that single-crystalline piezoelectric materials possess a higher thermal stability than PZT, their main disadvantage-low values of piezoelectric coefficients-is the reason why PZT is still used in the vast majority of cases.

The problem of the weak conversion of a mechanical deformation into an electrical signal by single-crystalline piezoelectric materials can be solved by utilizing complex constructions, such as unimorphs, bimorphs, or multilayer composites [27-31], but the presence of adhesive layers or grain boundaries in these composite transducers decreases the sensitivity, as well as the accuracy and thermal stability of the sensors. However, there is a way to manufacture a series bimorph for the piezoelectric sensing element and avoid bonding of separate plates by the formation of two domains with oppositely-directed spontaneous polarization vectors in a ferroelectric single-crystalline plate. If the crystallographic cut is correctly selected, such a "bidomain" crystal demonstrates a bimorph-like behavior, but does not comprise any interface except for an interdomain wall. Bending deformation of this single-crystalline bimorph causes the expansion of one domain and contraction of its counterpart. The voltages induced in the domains by the direct piezoelectric effect are added up; they are proportional to the bending magnitude at a fixed frequency. An example of the ferroelectric material which can be produced in a bidomain state is lithium niobate $\left(\mathrm{LiNbO}_{3}\right)$.

The phenomenon of the domain inversion in $\mathrm{LiNbO}_{3}$ in the course of a heat treatment near the Curie point was discovered by Ohnishi [32]. For the first time, large-area bidomain lithium niobate (b-LN) wafers were produced by Nakamura et al. $[33,34]$ and then investigated by numerous researchers [33-46]. Initially, b-LN single crystals were proposed as a possible replacement of composite bimorphs, glued by epoxy resins in precise movement systems, and for energy harvesting applications [33,34,39-41,47,48]. Recently, we have shown the possibility to apply b-LN for the conversion of oscillatory deformations to electrical signals [49-52] in vibrational sensors as well as in laminate magnetoelectric composites (b-LN/Metglas ${ }^{\circledR}$ ), with a record value of sensitivity to magnetic field as low as $200 \mathrm{fT}$ at a frequency of $6862 \mathrm{~Hz}$ [51]. Lithium niobate exhibits high thermal stability of piezoelectric coefficients, elastic properties, and electromechanical coupling factors for different cuts [53-55], and, moreover, possesses lead-free composition, which make it a promising candidate for the substitution of the commonly used PZT ceramics in low-frequency sensing and actuation applications.

\section{Materials and Methods}

In this paper we report the use of a single-crystalline b-LN plate for detecting low-frequency mechanical vibrations. A long and narrow rectangular sample with dimensions of $75 \times 5 \times 0.5 \mathrm{~mm}^{3}$ was cut from a commercial single-domain $\mathrm{LiNbO}_{3}$ wafer (ELAN Company Ltd., Saint-Petersburg, Russia) with the $y+128^{\circ}$ crystallographic orientation. Two oppositely polarized ferroelectric domains (so-called "head-to-head" bidomain structure) were formed in the plate by the diffusion annealing technique $[32,34,42]$. The detailed description of the b-LN preparation procedure can be found in Appendix A. Then tantalum electrodes were deposited on the opposite faces of the b-LN crystal by DC (direct current) magnetron sputtering. The quality of the bidomain structure was tested using a cantilever-type fastening by measuring the free end deflection under an applied external voltage, by a technique described in detail elsewhere [51]; the $k$-factor revealing the quality of the produced bidomain structure was determined to be as high as $33.1 \mathrm{pm} / \mathrm{V}$, which is only $18 \%$ lower than the theoretically predicted value $\left(k_{\mathrm{y}+128^{\circ}}=1.5 \cdot d_{23}=40.4 \mathrm{pm} / \mathrm{V}\right)$. 
We also prepared another LN sample with the same size, crystallographic orientation, and electrode type, but having a single-domain ferroelectric structure. This specimen was used for the evaluation of the external electromagnetic noise floor.

Finally, the b-LN crystal and its single-domain counterpart were clamped by two stainless-steel screws with nuts as a cantilever, with a length of $70 \mathrm{~mm}$ in a home-made fastening tool containing a polycrystalline alumina base, two gaskets, and two clamps. Two strips made of aluminum foil pressed by clamps to the tantalum electrodes were used for transferring the generated voltage to a coaxial cable and then to the measuring system (Figure 1).

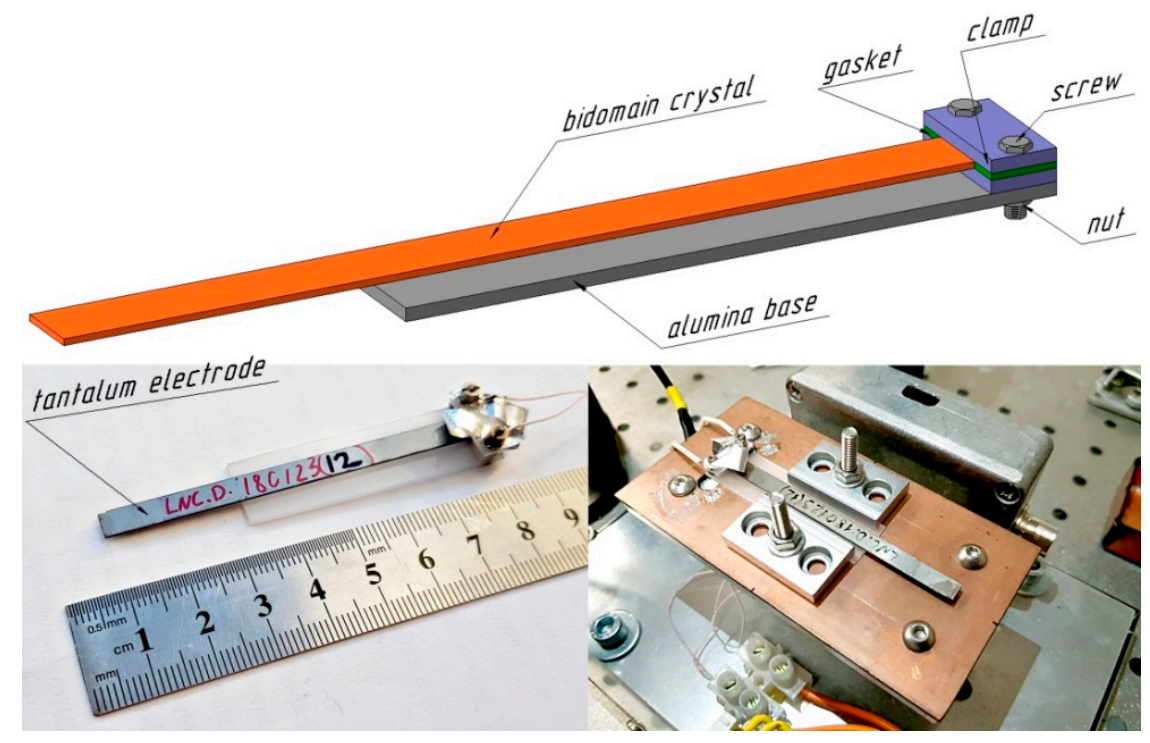

Figure 1. Schematic representation (top) and photography of the sensor prototype alone (bottom left) and mounted on the shaker (bottom right); the shielding box was removed. The labeling on the bidomain crystal was added for its identification.

In order to excite vibrations with ultra-low magnitude and frequency (down to $0.1 \mathrm{~nm}$ and $1 \mathrm{~Hz}$, respectively) we used a home-made piezoelectric shaker based on two similar PZT tubes (ceramic type APC 850, APC International Ltd., Mackeyville, PA, USA), with a length of $40 \mathrm{~mm}$, and inner and outer diameters of 10 and $11 \mathrm{~mm}$, respectively. These tubes were placed vertically on a massive steel plate fixed on a pneumatically stabilized optical table (Standa Ltd., Vilnius, Lithuania). The sensor prototype was mounted on a light aluminum platform fastened on the top of the PZT tubes. Finally, the sensor was shielded by a grounded copper box to reduce the electromagnetic noise from external sources.

Mechanical vibrations were excited by applying an AC voltage from an external signal generator to the PZT tubes connected in parallel. In the present study we used only pure sine excitations with low magnitudes and frequencies (less than $11.5 \mathrm{~V}$ and $150 \mathrm{~Hz}$, respectively), so that the excitation of the PZT tubes was always linear with respect to the applied ac signal.

The measurements of sensitivity to the vibrational impact were carried out at room temperature in an air ambient. We used two different techniques for the measurement of the sensor response to the external mechanical vibrations:

(i) Lock-in detection of the voltage amplitude by a SR-830 amplifier (Stanford Research Systems Inc., Sunnyvale, CA, USA);

(ii) Registration of oscillograms by a DSO-X 3032A oscilloscope (Agilent Technologies Inc., Santa Clara, CA, USA) with post-processing by the Fourier analysis.

Both the techniques were implemented without any additional preamplification of the initial signal collected from the b-LN sensitive element. As a consequence, the impedances of the sensor and measuring instrument were not matched. For this reason, the amplitude values of the signals collected 
by the setups were corrected with respect to the impedances of the measuring instrument, cables, and samples in order to compute the open-circuit voltage generated by the sensitive b-LN element.

The description of the used setup configurations, impedance measurements, as well as the details of the correction of the collected signals are presented in Appendix B.

The measurements of the sensor sensitivity by method (i) were carried out at four different excitation amplitudes. The voltages corresponding to vertical movements of the sensor amounting to $0.1,1,10$, and $100 \mathrm{~nm}$ were applied to the PZT tubes of the shaker (note that here we operate with amplitude values, so that the peak-to-peak oscillations were twice as large). Method (ii) was implemented by applying a sine voltage signal with an amplitude of $11.5 \mathrm{~V}$ to the PZT tubes, which corresponds to a $161 \mathrm{~nm}$ oscillation. In addition, the electromagnetic and acoustic noise floors were measured on the single-domain and bidomain crystals, respectively.

\section{Results and Discussion}

The results of the sensitivity measurements are shown in Figure 2. The generated voltage was relatively strong even at the minimal displacement amplitude of $0.1 \mathrm{~nm}$, and exceeded the acoustic noise level in almost the entire frequency range studied. Indeed, sine vibrations with displacement amplitudes of $0.1,1,10$, and $100 \mathrm{~nm}$ could be confidently detected at frequencies higher than $38,23,14$, and $7 \mathrm{~Hz}$, respectively. The acoustic noise floor measured from the sensor without any excitation was lower than $10 \mu \mathrm{V}$ in almost the entire frequency range. There were two sharp noise peaks in the graph related to zero excitation: one was near the resonance frequency of $97.25 \mathrm{~Hz}$ and the other at $50 \mathrm{~Hz}$, which is the power line frequency in Russia. Below approximately $30 \mathrm{~Hz}$, the acoustic noise started to steadily increase with decreasing frequency, reaching a maximum value of ca. $100 \mu \mathrm{V}$ near $7 \mathrm{~Hz}$. We ascribe the signal's behavior to some low-frequency sound source or residual mechanical vibrations. The acoustic nature of this noise source was confirmed by the electromagnetic noise floor acquired from the single-domain cantilever that demonstrated a low-frequency noise behavior $(1 / f$ flicker $)$ having a different shape.

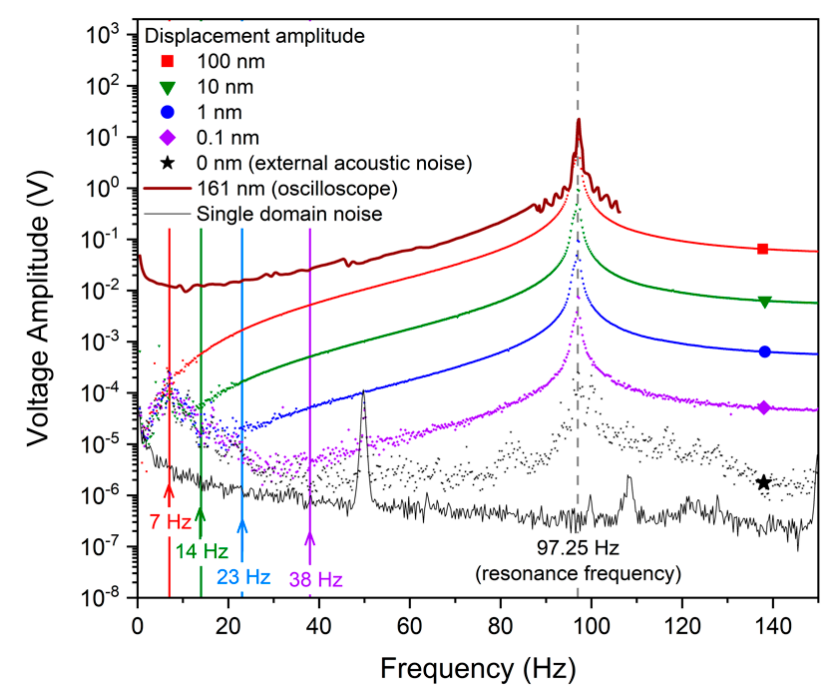

Figure 2. Voltage generated by the sensor being subject to sine vibrational excitations with different displacement amplitudes.

The signal measured by the oscilloscope possessed a slightly different shape in comparison to the lock-in results, especially at frequencies below $50 \mathrm{~Hz}$. It was clear that a sharper line was a result of calculation errors, which are imminent when the FFT computing is utilized for finite signals in the time domain. However, the low-frequency part of the plot was mainly influenced by the low input impedance of the oscilloscope that forms a high-pass filter with the impedance of the b-LN crystal. 
A mechanical quality factor calculated for the resonance peak was ca. 328 for measurements with all intensities of the vibrational excitation used in the present work.

The dependencies of the generated voltage on the displacement amplitude were linear in almost the entire investigated range (Figure 3a). An exception from this trend was only the data obtained in the oscilloscope measurements; the main reason for such a behavior was discussed above. As the experimental data at a fixed frequency were straight lines that differed only in their slopes, we could get the sensitivity to the vibrational amplitude normalized to a $1 \mathrm{~nm}$ displacement simply by calculating a linear fit for each frequency and taking the first-order term (Figure $3 b$ ). The plot of the sensitivity to a $1 \mathrm{~nm}$ displacement confidently followed the graph of the signal, which was obtained at a $1 \mathrm{~nm}$ excitation (Figure 2) down to a frequency of $23 \mathrm{~Hz}$, where the sensitivity reached its minimum value of $20 \mu \mathrm{V} / \mathrm{nm}$. A discrepancy at low frequencies was associated with an increasing contribution of the noise and, as a consequence, a worse linear fit. The peak value of the sensitivity to oscillatory displacements was reached at the resonance frequency and equaled $92.5 \mathrm{mV} / \mathrm{nm}$.

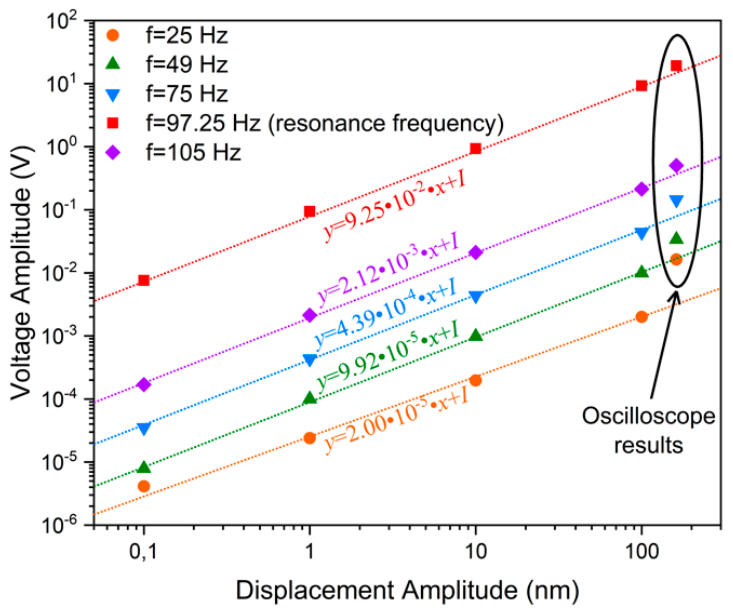

(a)

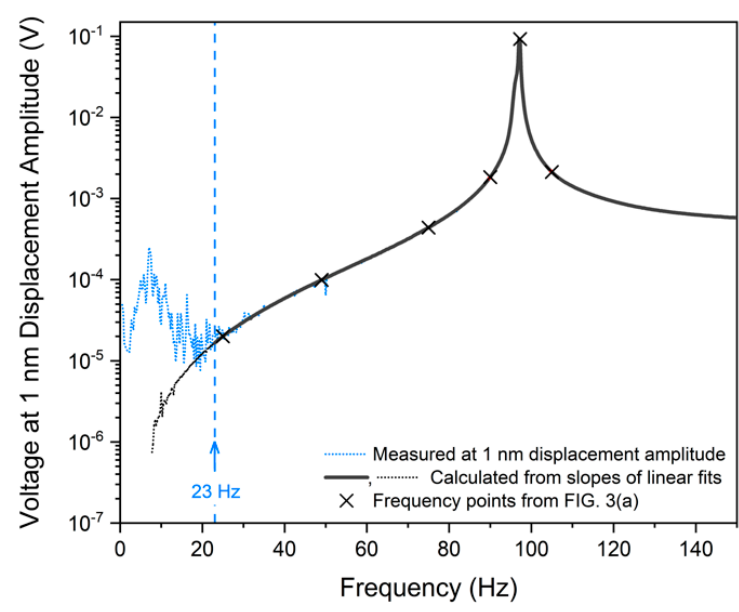

(b)

Figure 3. (a) Voltage generated by the sensor upon sine vibrations as a function of the displacement amplitude (the $I$ terms in the line equations in panel (a) are points of intercept defined by the acoustic noise; $I<5 \mu \mathrm{V}$ for all linear graphs shown); (b) sensitivity plot representing slopes of the linear responses to vibrations at all investigated frequencies (oscilloscope results neglected) and compared with the data for a $1 \mathrm{~nm}$ excitation displacement amplitude.

Finally, we computed the sensitivity of our sensor to the acceleration amplitude in units of the gravitational acceleration $g=9.81 \mathrm{~m} / \mathrm{s}^{2}$. Due to the weak intensity and low frequency of the used driving signals and, consequently, the high accuracy of the transformation of the AC (alternating current) voltage into oscillating deflections, the vibration at a fixed frequency had a strongly sinusoidal character. This means that the acceleration sensitivity could be easily calculated just by dividing the displacement sensitivity by a factor of $4 \cdot \pi^{2} \cdot f^{2} \cdot g^{-1}$, as the acceleration is the second derivative of the displacement. Figure 4 shows that the highest sensitivity of the sensor reached a value of $2443 \mathrm{~V} / \mathrm{g}$ at a resonance frequency of $97.25 \mathrm{~Hz}$, and decreased to ca. $7 \mathrm{~V} / \mathrm{g}$ to the left and to the right from the maximum point. 


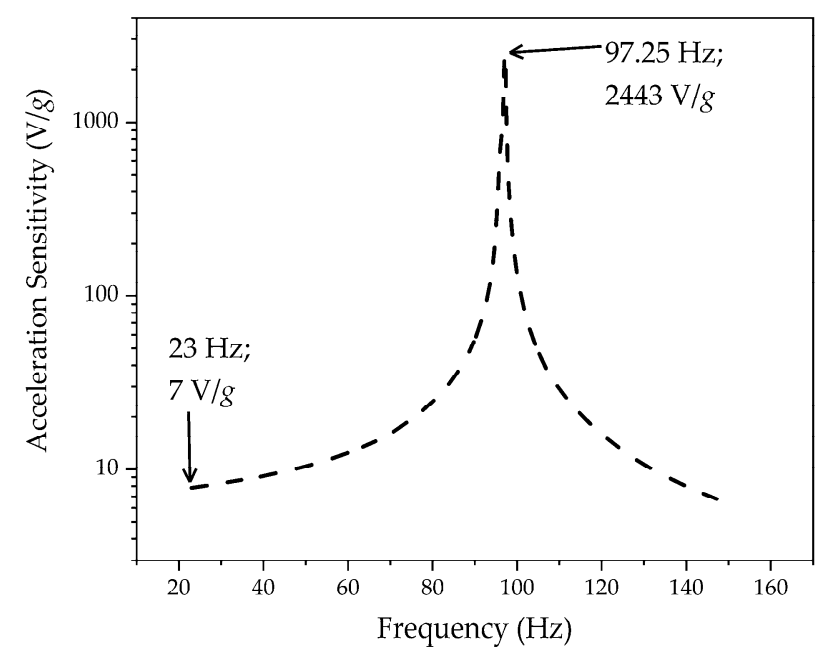

Figure 4. Sensitivity of the sensor to acceleration in units of $g$.

\section{Conclusions}

To conclude, a vibrational sensor based on a bidomain $\mathrm{LiNbO}_{3}$ (b-LN) single crystal was developed and investigated. The sensitive element was made of a rectangular $\mathrm{b}-\mathrm{LN}$ plate fastened as a cantilever in a polycrystalline alumina clamp. We used a home-made piezoelectric shaker, as well as two different voltage measurement setups based on a lock-in and on an oscilloscope, respectively. The sensor demonstrates the ability to detect sine vibrations with displacement amplitudes down to $0.1 \mathrm{~nm}$ at frequencies higher than $38 \mathrm{~Hz}$ without any preamplification. Vibrations with a larger amplitude of, for example, $100 \mathrm{~nm}$ allow the detection limit to be pulled down to a frequency of $7 \mathrm{~Hz}$. Moreover, the sensor's output voltage at a fixed frequency demonstrates a linear response to the increasing displacement amplitude. The displacement response to low-amplitude sine vibrational excitations was measured to be equal to $92.5 \mathrm{mV} / \mathrm{nm}$ at the resonance frequency of $97.25 \mathrm{~Hz}$, and to $20 \mu \mathrm{V} / \mathrm{nm}$ at $23 \mathrm{~Hz}$. The obtained maximum value of the acceleration sensitivity reaches $2443 \mathrm{~V} / \mathrm{g}$ when the sensor is oscillatory excited at resonance. Our device is quite competitive with the sensors based on PZT, polyvinylidene difluoride (PVDF), or ZnO [11,14,18-21,56]. It possesses the same or a higher sensitivity as compared to the best results published $(2 \mathrm{mV} / \mathrm{nm}$ at a resonance frequency of $48 \mathrm{~Hz}$ for a cantilever based on a PZT fiber composite [21], and $170 \mathrm{~V} / \mathrm{g}$ at a resonance frequency of $53.6 \mathrm{~Hz}$ for a cantilever based on a PZT bulk ceramic [19]). A more detailed comparison with the literature data can be found in Appendix C.

The high thermal and chemical stability of lithium niobate, as well as an efficient conversion of mechanical deformations to voltage, makes the b-LN crystals a promising material for highly sensitive applications, including low-frequency vibrational sensors able to withstand harsh environments and high temperatures.

Author Contributions: Conceptualization, I.V.K., M.D.M., A.M.K., and A.V.T.; methodology, I.V.K. and A.V.T.; software, I.V.K. and A.S.B.; validation, I.V.K., A.V.T., D.A.K., and M.D.M.; formal analysis, M.D.M.; investigation, I.V.K., A.A.T., and R.N.Z.; resources, A.M.K.; data curation, I.V.K.; writing-original draft preparation, I.V.K.; writing-review and editing, A.V.T. and N.A.S.; visualization, A.V.T. and I.V.K.; supervision, M.D.M. and Y.N.P.; project administration, Y.N.P.; funding acquisition, Y.N.P.

Funding: The study was supported by the Ministry of Education and Science of the Russian Federation (Federal Targeted Programme for Research and Development in Priority Areas of Development of the Russian Scientific and Technological Complex for 2014-2020) (Project ID RFMEFI57816X0187).

Conflicts of Interest: The authors declare no conflicts of interest. 


\section{Appendix A}

We used the so-called diffusion annealing (DA) technique in order to form a ferroelectric "head-to-head" bidomain structure in a LN plate. A single-domain plate for sensing element having the above-mentioned dimensions, as well as a reference specimen with dimensions of $10 \times 10 \times 0.5 \mathrm{~mm}^{3}$, were washed in acetone and distilled deionized water in order to remove surface dirt. Then we placed the crystals in a quartz cylinder and annealed them in an air ambient at $1140{ }^{\circ} \mathrm{C}$ for $5 \mathrm{~h}$. Heating and cooling rates of $300^{\circ} \mathrm{C} / \mathrm{h}$ were selected. After annealing, an angle lap of the reference specimen was prepared and etched in a HF:HNO3 = 2:1(vol.) mixture for the visualization of the domain structure according to [57]. As it is clearly seen in Figure A1, $5 \mathrm{~h}$ was sufficient for a polarization reversal in a half of the sample.

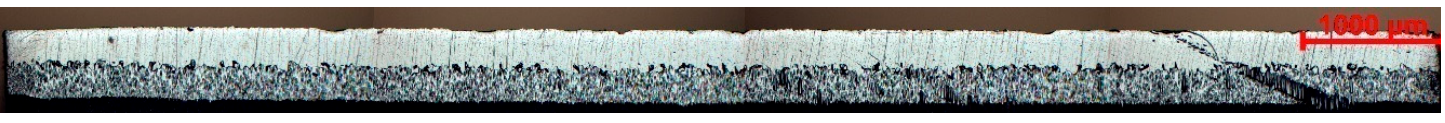

Figure A1. Panoramic photograph of an etched angle lap prepared in the reference specimen that was annealed in the same run as the sensing element.

The formation of the bidomain ferroelectric structure can be explained in terms of $\mathrm{Li}_{2} \mathrm{O}$ out-diffusion from the crystal during the thermal treatment. Indeed, the concentration gradient inside the crystal causes the occurrence of a built-in electric field and accompanied growth of two oppositely polarized domains [43].

\section{Appendix B}

Excitations of mechanical vibrations were provided by applying a sinusoidal voltage signal to the piezoelectric PZT (lead zirconate titanate) tubes. According to the equation of linear piezoelectricity, the deformation of the PZT tube is proportional to the applied voltage. Indeed, for the used ceramic cylinder the static deformation $\delta$ can be calculated as $\delta(\mathrm{nm})=-14 \cdot U(V)$, where $U$ is the applied voltage. This law is observed at small deformations and far from the resonance frequency, which was estimated to be higher than $5 \mathrm{kHz}$ for the whole shaker. Due to the use of ultra-weak low-frequency vibrational excitations in the study, we avoid the undesirable contribution of the non-linear converse piezoelectric effect, so that the excitation of the PZT tubes was always directly proportional to the applied ac signal.

We used two different techniques for the measurement of the sensor response to the external mechanical vibrations:

(i) Lock-in detection of the voltage amplitude by a SR-830 amplifier (Stanford Research Systems Inc., Sunnyvale, CA, USA);

(ii) Registration of oscillograms by a DSO-X 3032A oscilloscope, with post-processing by the Fourier analysis (Agilent Technologies Inc., Santa Clara, CA, USA).

Method (i) was utilized for measuring the maximum possible sensitivity of the sensor with respect to external acoustic and electromagnetic noise. We used the ac signal from the internal generator of the lock-in for the excitation of the shaker and then registered the sensor response. Since the lock-in detection allows registration of the voltage with a high signal-to-noise ratio, it is possible to measure signals caused by ultra-weak sub-nm vibrations. The measured rms (root mean square) amplitude was collected to a computer through a Keysight 82357B GPIB interface (Calabasas, CA, USA) (Figure A2a).

All the lock-in data were obtained with a frequency step of $0.25 \mathrm{~Hz}$ and a bandwidth of the input low-pass filter of $0.23 \mathrm{~Hz}$, with an averaging of 1000 points at each frequency. Though the lock-in detection is a very powerful method for measuring low-amplitude or noisy signals, it needs a periodic reference signal and; therefore, this technique is unlikely to be used in commercial vibrational sensors. Therefore, we performed the measurement by method (ii), where the signal in the time 
domain was registered by the digital oscilloscope. In this case sine vibrations were excited by an external arbitrary waveform generator (Owon AG4151, Zhangzhou, China) with a frequency step of $2 \mathrm{~Hz}$ (Figure A2b). After the data collection, every oscillogram was processed by a script written in the GNU Octave (version 4.2.1) software. Assuming there is no information about the initial vibration, the program decomposed the time-domain signal into a spectrum in the frequency domain by using the fast Fourier transform (FFT) algorithm, and extracted information about the frequency and amplitude of the voltage generated by the sensor. Finally, we revealed a correspondence between the vibration amplitudes and absolute values of the measured responses at exciting signal frequencies.

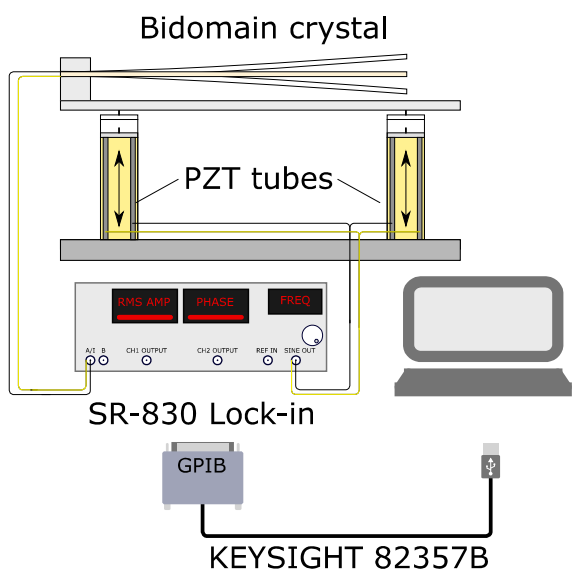

(a)

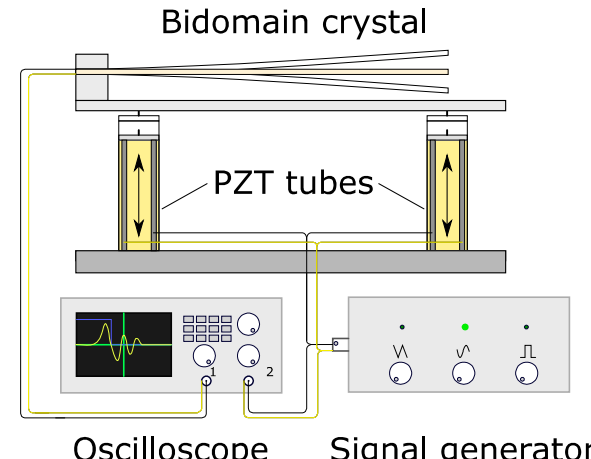

(b)

Figure A2. Diagrams of (a) lock-in and (b) oscilloscope-based techniques used in the study.

Both the techniques were implemented without any additional preamplification of the initial signal collected from the b-LN sensitive element. This means that the impedances of the sensor and measuring instrument were not matched, hence a correction of the collected signal was needed. Ignoring the resistances of the wires and all inductivities, a simplified equivalent circuit of the measuring system with the connected sensor includes an AC voltage generator $V_{c r}$, with its series impedance $Z_{c r}$ representing the piezoelectric crystal, a capacitance $C_{i n}(25 \mathrm{pF}$ for the lock-in and $14 \mathrm{pF}$ for the oscilloscope), a resistance of the measuring instrument $R_{\text {in }}(10 \mathrm{M} \Omega$ for the lock-in and $1 \mathrm{M} \Omega$ for the oscilloscope), and a capacitance $C_{w}$ of the coaxial cable used in the experiment (Figure A3).

The impedances of the connecting wires and measuring input can be combined in a total impedance of the measurement system $Z_{m}$ :

$$
Z_{m}=R_{i n} \|\left(C_{w}+C_{i n}\right)=\left(\frac{1}{R_{i n}}+j 2 \pi f\left(C_{w}+C_{i n}\right)\right)^{-1}=\frac{R_{i n}}{1+j 2 \pi f\left(C_{w}+C_{i n}\right) R_{i n}}
$$

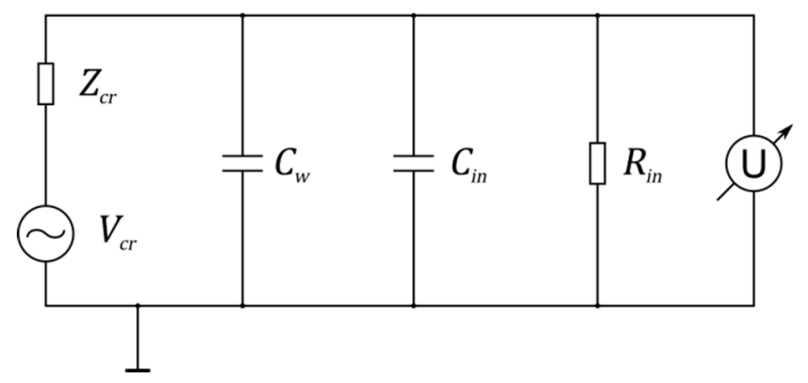

Figure A3. Simplified equivalent circuit for measuring of the voltage generated by the sensor. 
Thus, the open-circuit voltage generated by the vibrating crystal is:

$$
V_{c r}=U \cdot\left(1+\frac{Z_{c r}}{Z_{m}}\right)=U \cdot\left(1+\frac{Z_{c r}\left(1+j 2 \pi f\left(C_{w}+C_{i n}\right) R_{i n}\right)}{R_{i n}}\right)
$$

In order to determine the impedances of the single-domain and bidomain crystals, we used the lock-in setup. The internal reference signal source was connected to one of the sensing element's electrodes; the wire from the other electrode was connected to the input of the lock-in. A simplified equivalent circuit is shown in Figure A4. Here $V_{\text {out }}$ is the rms amplitude of the reference signal generated by the lock-in internal source; $U_{i m p}$ and $\varphi$ are the rms amplitude and phase shift of the detected signal, respectively; $R_{\text {out }}$ is the output resistance of the lock-in (50 $\left.\Omega\right) ; C_{w 1}$ and $C_{w 2}$ are the capacitances of the connecting wires; $Z_{i n}$ is the impedance of the lock-in, $Z_{i n}=R_{i n} \| C_{i n}=\frac{R_{i n}}{1+j 2 \pi f C_{i n} R_{i n}}$.

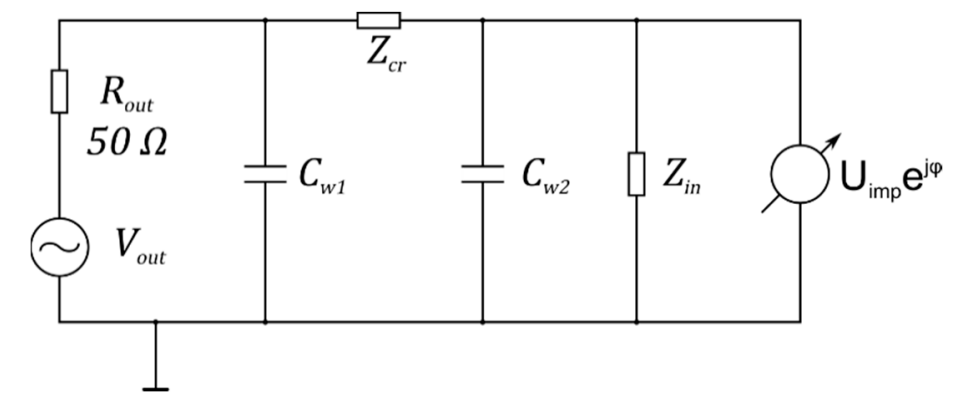

Figure A4. Simplified equivalent circuit for measuring of impedance by lock-in amplifier.

We can combine the impedances of the lock-in and the wire, connecting the sample and the setup, in a total impedance of the right-hand side of the circuit:

$$
Z_{\|}=Z_{i n} \| C_{w 2}
$$

The current through this impedance is equal to:

$$
i=\frac{V_{\text {out }} Z_{C w 1}}{R_{\text {out }} Z_{C w 1}+\left(Z_{\|}+Z_{c r}\right)\left(Z_{C w 1}+R_{o u t}\right)}
$$

So, the impedance of the crystal fastened in the vibrational sensor will be:

$$
\begin{gathered}
Z_{c r}=\frac{V_{\text {out }} Z_{C w 1} Z_{\|}-U R_{\text {out }} Z_{C w 1}}{U_{\text {imp }} e^{j \varphi}\left(Z_{C w 1}+R_{\text {out }}\right)}-Z_{\|} \\
=\frac{R_{\text {in }}}{1+j 2 \pi f\left(C_{w 2}+C_{i n}\right) R_{\text {in }}}\left(\frac{V_{\text {out }}}{U_{\text {imp }} e^{j \varphi}} \cdot \frac{1}{1+j 2 \pi f C_{w 1} R_{\text {out }}}-1\right)-\frac{R_{\text {out }}}{1+j 2 \pi f C_{w 1} R_{\text {out }}}
\end{gathered}
$$

We determined the impedances of the cantilever-fastened single-domain and bidomain lithium niobate crystals using the circuit shown in Figure A4 and Equation (A5). The resulting plots of the impedances are shown in Figure A5. Both the graphs possess a very similar shape at low frequencies, which reveals equal geometrical sizes and a good fastening of the piezoelectric cantilevers. There is a sharp feature in the plot of the impedance absolute value of the b-LN associated with the console bending resonance at a frequency of $97.25 \mathrm{~Hz}$. 


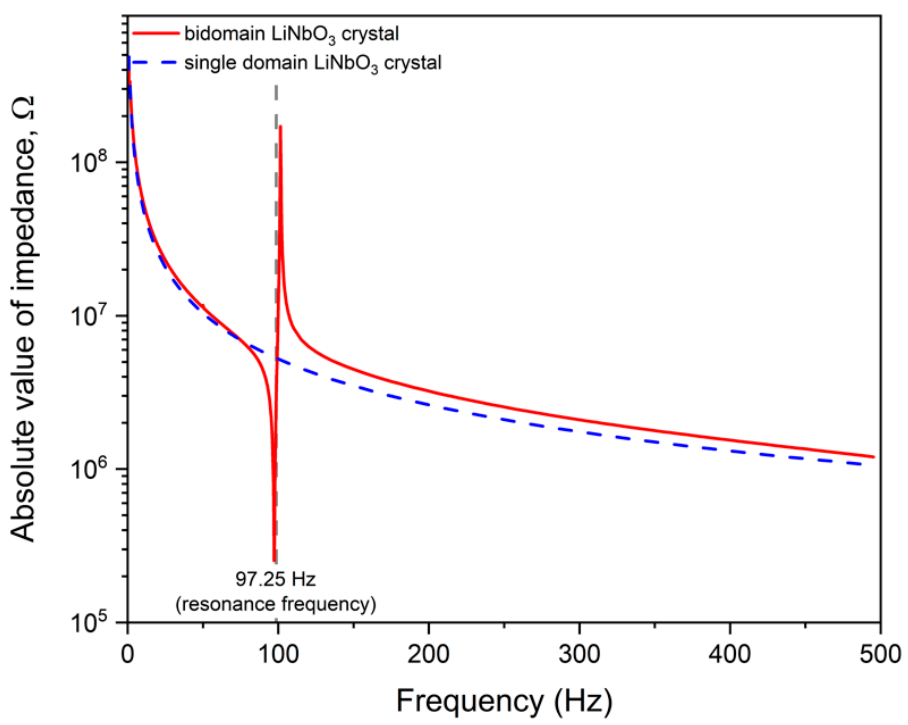

Figure A5. Impedances of the cantilever-fastened bidomain and single domain $\mathrm{LiNbO}_{3}$ crystals.

\section{Appendix C}

Table A1 briefly compares the sensitivity of the produced sensor with literature data.

Table A1. Comparison of the sensitivity of the produced sensor at the low-frequency excitation $(25 \mathrm{~Hz})$ and in the resonance conditions with literature data.

\begin{tabular}{|c|c|c|c|c|c|c|}
\hline \multirow[b]{2}{*}{ Sensor Type } & \multirow[b]{2}{*}{$\begin{array}{c}\text { Resonance } \\
\text { Frequency, } \\
\text { Hz }\end{array}$} & \multicolumn{2}{|c|}{ Sensitivity to Displacement } & \multicolumn{2}{|c|}{ Sensitivity to Acceleration } & \multirow[b]{2}{*}{ Reference } \\
\hline & & $\begin{array}{c}\text { At a } \\
\text { Frequency } \\
\text { of } 25 \mathrm{~Hz} \\
\text { V/nm } \\
\end{array}$ & $\begin{array}{c}\text { At the } \\
\text { Resonance } \\
\text { Frequency, } \\
\text { V/nm }\end{array}$ & $\begin{array}{c}\text { At a } \\
\text { Frequency } \\
\text { of } 25 \mathrm{~Hz}, \\
\mathrm{~V} / g\end{array}$ & $\begin{array}{l}\text { At the } \\
\text { Resonance } \\
\text { Frequency, } \\
\text { V/g }\end{array}$ & \\
\hline $\begin{array}{c}\text { PZT cantilever } \\
\text { with a seismic mass }\end{array}$ & 50 & - & - & 0.5 & 3.8 & {$[18]$} \\
\hline PZT thin film & 9610 & - & $3.5 \times 10^{-5}$ & - & - & [11] \\
\hline PZT cantilever & 53.6 & - & - & 10 & 170 & [19] \\
\hline $\begin{array}{c}\text { Polyvinylidene } \\
\text { difluoride (PVDF) } \\
\text { thin film }\end{array}$ & - & - & - & $2.35 \times 10^{-1}$ & - & [56] \\
\hline PZT fiber composite & 48 & $1 \times 10^{-5}$ & $2 \times 10^{-3}$ & - & - & [21] \\
\hline $\begin{array}{l}\text { Cantilever based on } \\
\mathrm{ZnO} \text { nanowires }\end{array}$ & 44.1 & - & $13 \times 10^{-8}$ & - & - & {$[14]$} \\
\hline PZT cantilever & 275 & - & - & $1 \times 10^{-3}$ & 4.5 & {$[20]$} \\
\hline $\begin{array}{l}\text { Bidomain lithium } \\
\text { niobate cantilever }\end{array}$ & 97.25 & $2 \times 10^{-5}$ & $3.5 \times 10^{-2}$ & 7 & 2443 & This work \\
\hline
\end{tabular}

\section{References}

1. Lynch, J.P. A Summary Review of Wireless Sensors and Sensor Networks for Structural Health Monitoring. Shock Vib. Dig. 2006, 38, 91-128. [CrossRef]

2. Zhao, X.; Gao, H.; Zhang, G.; Ayhan, B.; Yan, F.; Kwan, C.; Rose, J.L. Active health monitoring of an aircraft wing with embedded piezoelectric sensor/actuator network: I. Defect detection, localization and growth monitoring. Smart Mater. Struct. 2007, 16, 1208-1217. [CrossRef]

3. Ubertini, F.; Comanducci, G.; Cavalagli, N. Vibration-based structural health monitoring of a historic bell-tower using output-only measurements and multivariate statistical analysis. Struct. Health Monit. 2016, 15, 438-457. [CrossRef] 
4. He, Q.; Li, K.; Han, R.; Wang, J.; Li, X. Sub-g weak-vibration-triggered high-efficiency energy harvesting for event identification. J. Micromech. Microeng. 2018, 28, 075018. [CrossRef]

5. Wang, S.Y.; Quek, S.T.; Ang, K.K. Vibration control of smart piezoelectric composite plates. Smart Mater. Struct. 2001, 10, 637-644. [CrossRef]

6. Sharma, A.; Kumar, R.; Vaish, R.; Chauhan, V.S. Active vibration control of space antenna reflector over wide temperature range. Compos. Struct. 2015, 128, 291-304. [CrossRef]

7. Aridogan, U.; Basdogan, I. A review of active vibration and noise suppression of plate-like structures with piezoelectric transducers. J. Intell. Mater. Syst. Struct. 2015, 26, 1455-1476. [CrossRef]

8. Jiang, X.; Kim, K.; Zhang, S.; Johnson, J.; Salazar, G. High-Temperature Piezoelectric Sensing. Sensors 2013, 14, 144-169. [CrossRef]

9. Wang, W.; Xue, X.; Huang, Y.; Liu, X. A Novel Wireless and Temperature-Compensated SAW Vibration Sensor. Sensors 2014, 14, 20702-20712. [CrossRef]

10. Akiyama, M.; Kamohara, T.; Nishikubo, K.; Ueno, N.; Nagai, H.; Okutani, T. Ultrahigh temperature vibration sensors using aluminum nitride thin films and $\mathrm{W} / \mathrm{Ru}$ multilayer electrodes. Appl. Phys. Lett. 2005, 86, 022106. [CrossRef]

11. Yang, Z.; Wang, Q.-M. Transient response of piezoelectric thin-film vibration sensor under pulse excitation. J. Appl. Phys. 2006, 99, 014107. [CrossRef]

12. Castille, C.; Dufour, I.; Lucat, C. Longitudinal vibration mode of piezoelectric thick-film cantilever-based sensors in liquid media. Appl. Phys. Lett. 2010, 96, 154102. [CrossRef]

13. Tang, Q.C.; He, Q.S.; Li, M.Y.; Dong, C.; Xu, D.C.; Li, X. A self-powered wireless sensing node for event-driven alerting based on a bi-stable vibration energy harvester. In Proceedings of the 2015 Transducers-2015 18th International Conference on Solid-State Sensors, Actuators and Microsystems (TRANSDUCERS), Anchorage, AK, USA, 21-25 June 2015; pp. 1215-1218. [CrossRef]

14. Yu, A.; Jiang, P.; Wang, Z.L. Nanogenerator as self-powered vibration sensor. Nano Energy 2012, 1, 418-423. [CrossRef]

15. Egusa, S.; Iwasawa, N. Piezoelectric paints: Preparation and application as built-in vibration sensors of structural materials. J. Mater. Sci. 1993, 28, 1667-1672. [CrossRef]

16. Qiu, Z.; Zhang, X.; Wu, H.; Zhang, H. Optimal placement and active vibration control for piezoelectric smart flexible cantilever plate. J. Sound Vib. 2007, 301, 521-543. [CrossRef]

17. Tressler, J.F.; Alkoy, S.; Newnham, R.E. Piezoelectric Sensors and Sensor Materials. J. Electroceram. 1998, 2, 257-272. [CrossRef]

18. Ou, Q.; Chen, X.; Gutschmidt, S.; Wood, A.; Leigh, N.; Arrieta, A.F. An experimentally validated double-mass piezoelectric cantilever model for broadband vibration-based energy harvesting. J. Intell. Mater. Syst. Struct. 2012, 23, 117-126. [CrossRef]

19. Hu, Y.; Tu, H.; Xu, Y. Low-frequency vibration sensors based on a cascaded gapped cantilever. Smart Mater. Struct. 2016, 25, 095007. [CrossRef]

20. Bong, Y.J.; Kok, S.L. Characterization on Piezoelectric Cantilever for its Linear Response at Low Frequency for Measuring Acceleration Level of Vibration. Appl. Mech. Mater. 2015, 761, 579-583. [CrossRef]

21. Chen, Q.; Sun, Y.; Wang, Q.M.; Qin, L.; Xue, H.; Xiong, Z. Piezoelectric PZT fiber composite as a low frequency vibration sensor. In Proceedings of the 2013 Joint IEEE International Symposium on Applications of Ferroelectric and Workshop on Piezoresponse Force Microscopy (ISAF/PFM), Prague, Czech Republic, 21-25 July 2013; pp. 302-305. [CrossRef]

22. Mecea, V.M. Loaded vibrating quartz sensors. Sens. Actuators A Phys. 1994, 40, 1-27. [CrossRef]

23. Ansorge, E.; Schimpf, S.; Hirsch, S.; Sauerwald, J.; Fritze, H.; Schmidt, B. Evaluation of langasite $\left(\mathrm{La}_{3} \mathrm{Ga}_{5} \mathrm{SiO}_{14}\right)$ as a material for high temperature microsystems. Sens. Actuators A Phys. 2006, 130-131, 393-396. [CrossRef]

24. Turner, R.C.; Fuierer, P.A.; Newnham, R.E.; Shrout, T.R. Materials for high temperature acoustic and vibration sensors: A review. Appl. Acoust. 1994, 41, 299-324. [CrossRef]

25. Kim, K.; Zhang, S.; Salazar, G.; Jiang, X. Design, fabrication and characterization of high temperature piezoelectric vibration sensor using YCOB crystals. Sens. Actuators A Phys. 2012, 178, 40-48. [CrossRef]

26. Zhang, S.; Yu, F. Piezoelectric Materials for High Temperature Sensors. J. Am. Ceram. Soc. 2011, 94, $3153-3170$. [CrossRef] 
27. Yuan, Y.; Shyong Chow, K.; Du, H.; Wang, P.; Zhang, M.; Yu, S.; Liu, B. A ZnO thin-film driven microcantilever for nanoscale actuation and sensing. Int. J. Smart Nano Mater. 2013, 4, 128-141. [CrossRef]

28. Kawamata, A.; Hosaka, H.; Morita, T. Non-hysteresis and perfect linear piezoelectric performance of a multilayered lithium niobate actuator. Sens. Actuators A Phys. 2007, 135, 782-786. [CrossRef]

29. Kim, H.S.; Kim, J.-H.; Kim, J. A review of piezoelectric energy harvesting based on vibration. Int. J. Precis. Eng. Manuf. 2011, 12, 1129-1141. [CrossRef]

30. Karami, M.A.; Bilgen, O.; Inman, D.J.; Friswell, M.I. Experimental and analytical parametric study of single-crystal unimorph beams for vibration energy harvesting. IEEE Trans. Ultrason. Ferroelectr. Freq. Control 2011, 58, 1508-1520. [CrossRef] [PubMed]

31. Wlodkowski, P.A.; Deng, K.; Kahn, M. The development of high-sensitivity, low-noise accelerometers utilizing single crystal piezoelectric materials. Sens. Actuators A Phys. 2001, 90, 125-131. [CrossRef]

32. Ohnishi, N. An Etching Study on a Heat-Induced Layer at the Positive-Domain Surface of $\mathrm{LiNbO}_{3}$. Jpn. J. Appl. Phys. 1977, 16, 1069-1070. [CrossRef]

33. Nakamura, K.; Ando, H.; Shimizu, H. Partial Domain Inversion in $\mathrm{LiNbO}_{3}$ Plates and its Applications to Piezoelectric Devices. In Proceedings of the IEEE 1986 Ultrasonics Symposium, Williamsburg, VA, USA, 17-19 November 1986; pp. 719-722. [CrossRef]

34. Nakamura, K.; Ando, H.; Shimizu, H. Ferroelectric domain inversion caused in $\mathrm{LiNbO}_{3}$ plates by heat treatment. Appl. Phys. Lett. 1987, 50, 1413-1414. [CrossRef]

35. Kubasov, I.V.; Kislyuk, A.M.; Bykov, A.S.; Malinkovich, M.D.; Zhukov, R.N.; Kiselev, D.A.; Ksenich, S.V.; Temirov, A.A.; Timushkin, N.G.; Parkhomenko, Y.N. Bidomain structures formed in lithium niobate and lithium tantalate single crystals by light annealing. Crystallogr. Rep. 2016, 61, 258-262. [CrossRef]

36. Blagov, A.E.; Bykov, A.S.; Kubasov, I.V.; Malinkovich, M.D.; Pisarevskii, Y.V.; Targonskii, A.V.; Eliovich, I.A.; Kovalchuk, M.V. An electromechanical X-ray optical element based on a hysteresis-free monolithic bimorph crystal. Instrum. Exp. Tech. 2016, 59, 728-732. [CrossRef]

37. Bykov, A.S.; Malinkovich, M.D.; Kubasov, I.V.; Kislyuk, A.M.; Kiselev, D.A.; Ksenich, S.V.; Zhukov, R.N.; Temirov, A.A.; Chichkov, M.V.; Polisan, A.A.; et al. Application of Radioactive Isotopes for Beta-Voltaic Generators. Russ. Microelectron. 2017, 46. [CrossRef]

38. Kubasov, I.V.; Popov, A.V.; Bykov, A.S.; Temirov, A.A.; Kislyuk, A.M.; Zhukov, R.N.; Kiselev, D.A.; Chichkov, M.V.; Malinkovich, M.D.; Parkhomenko, Y.N. Deformation Anisotropy of $\mathrm{Y}+128^{\circ}$-Cut Single Crystalline Bidomain Wafers of Lithium Niobate. Russ. Microelectron. 2017, 46, 557-563. [CrossRef]

39. Nakamura, K.; Ando, H.; Shimizu, H. Bending Vibrator Consisting of a $\mathrm{LiNbO}_{3}$ Plate with a Ferroelectric Inversion Layer. Jpn. J. Appl. Phys. 1987, 26, 198. [CrossRef]

40. Nakamura, K.; Shimizu, H. Hysteresis-free piezoelectric actuators using $\mathrm{LiNbO}_{3}$ plates with a ferroelectric inversion layer. Ferroelectrics 1989, 93, 211-216. [CrossRef]

41. Nakamura, K.; Nakamura, T.; Yamada, K. Torsional Actuators Using $\mathrm{LiNbO}_{3}$ Plates with an Inversion Layer. Jpn. J. Appl. Phys. 1993, 32, 2415-2417. [CrossRef]

42. Kugel, V.D.; Rosenman, G. Domain inversion in heat-treated $\mathrm{LiNbO}_{3}$ crystals. Appl. Phys. Lett. 1993, 62, 2902-2904. [CrossRef]

43. Rosenman, G.; Kugel, V.D.; Shur, D. Diffusion-induced domain inversion in ferroelectrics. Ferroelectrics 1995, 172, 7-18. [CrossRef]

44. Antipov, V.V.; Bykov, A.S.; Malinkovich, M.D.; Parkhomenko, Y.N. Formation of bidomain structure in lithium niobate single crystals by electrothermal method. Ferroelectrics 2008, 374, 65-72. [CrossRef]

45. Bykov, A.S.; Grigoryan, S.G.; Zhukov, R.N.; Kiselev, D.A.; Ksenich, S.V.; Kubasov, I.V.; Malinkovich, M.D.; Parkhomenko, Y.N. Formation of bidomain structure in lithium niobate plates by the stationary external heating method. Russ. Microelectron. 2014, 43, 536-542. [CrossRef]

46. Kubasov, I.V.; Timshina, M.S.; Kiselev, D.A.; Malinkovich, M.D.; Bykov, A.S.; Parkhomenko, Y.N. Interdomain region in single-crystal lithium niobate bimorph actuators produced by light annealing. Crystallogr. Rep. 2015, 60, 700-705. [CrossRef]

47. Funasaka, T.; Furuhata, M.; Hashimoto, Y.; Nakamura, K. Piezoelectric generator using a $\mathrm{LiNbO}_{3}$ plate with an inverted domain. In Proceedings of the 1998 IEEE Ultrasonics Symposium (Cat. No. 98CH36102), Sendai, Japan, 5-8 October 1998; Volume 1, pp. 959-962. [CrossRef] 
48. Kubasov, I.V.; Kislyuk, A.; Malinkovich, M.; Temirov, A.A.; Ksenich, S.V.; Kiselev, D.A.; Bykov, A.S.; Parkhomenko, Y.N. Vibrational Power Harvester Based on Lithium Niobate Bidomain Plate. Acta Phys. Pol. A 2018, 134, 90-92. [CrossRef]

49. Vidal, J.V.; Turutin, A.V.; Kubasov, I.V.; Malinkovich, M.D.; Parkhomenko, Y.N.; Kobeleva, S.P.; Kholkin, A.L.; Sobolev, N.A. Equivalent Magnetic Noise in Magnetoelectric Laminates Comprising Bidomain $\mathrm{LiNbO}_{3}$ Crystals. IEEE Trans. Ultrason. Ferroelectr. Freq. Control 2017, 64, 1102-1119. [CrossRef] [PubMed]

50. Turutin, A.V.; Vidal, J.V.; Kubasov, I.V.; Kislyuk, A.M.; Malinkovich, M.D.; Parkhomenko, N.; Kobeleva, S.P.; Kholkin, A.L.; Sobolev, N.A. Low-frequency magnetic sensing by magnetoelectric metglas/bidomain $\mathrm{LiNbO}_{3}$ long bars. J. Phys. D Appl. Phys. 2018, 51, 214001. [CrossRef]

51. Turutin, A.V.; Vidal, J.V.; Kubasov, I.V.; Kislyuk, A.M.; Malinkovich, M.D.; Parkhomenko, Y.N.; Kobeleva, S.P.; Pakhomov, O.V.; Kholkin, A.L.; Sobolev, N.A. Magnetoelectric metglas/bidomain y $+140^{\circ}$-cut lithium niobate composite for sensing fT magnetic fields. Appl. Phys. Lett. 2018, 112, 262906. [CrossRef]

52. Kubasov, I.V.; Kislyuk, A.M.; Malinkovich, M.D.; Temirov, A.A.; Ksenich, S.V.; Kiselev, D.A.; Bykov, A.S.; Parkhomenko, Y.N. A Novel Vibration Sensor Based on Bidomain Lithium Niobate Crystal. Acta Phys. Pol. A 2018, 134, 106-108. [CrossRef]

53. Yamada, T.; Niizeki, N.; Toyoda, H. Piezoelectric and Elastic Properties of Lithium Niobate Single Crystals. Jpn. J. Appl. Phys. 1967, 6, 151-155. [CrossRef]

54. Smith, R.T.; Welsh, F.S. Temperature Dependence of the Elastic, Piezoelectric, and Dielectric Constants of Lithium Tantalate and Lithium Niobate ARTICLES YOU MAY BE INTERESTED IN Determination of Elastic and Piezoelectric Constants for Crystals in Class (3 m). J. Appl. Phys. 1971, 42, 2219. [CrossRef]

55. Chen, F.; Kong, L.; Song, W.; Jiang, C.; Tian, S.; Yu, F.; Qin, L.; Wang, C.; Zhao, X. The electromechanical features of $\mathrm{LiNbO}_{3}$ crystal for potential high temperature piezoelectric applications. J. Mater. 2018. [CrossRef]

56. Wan, Z.; Ji, T.; Shang, Y.Y. PVDF Piezoelectric Film Accelerometer for Low Frequency and Ultra-Low Frequency. Appl. Mech. Mater. 2011, 63-64, 465-469. [CrossRef]

57. Nassau, K.; Levinstein, H.J.; Loiacono, G.M. The domain structure and etching of ferroelectric lithium niobate. Appl. Phys. Lett. 1965, 6, 228-229. [CrossRef]

(C) 2019 by the authors. Licensee MDPI, Basel, Switzerland. This article is an open access article distributed under the terms and conditions of the Creative Commons Attribution (CC BY) license (http:/ / creativecommons.org/licenses/by/4.0/). 